\title{
Mathematical model of Behavior Control Mechanism
}

\author{
Jingxian Zuo, Jian Bai \\ Hebei Vocational \& Technical College of Building Materials, Hebei \\ Qinhuangdao066400
}

Keywords: Behavior control, Math model, Motivation, Constraint

\begin{abstract}
One important content for management is to conduct effective control on actions of person to be managed, which is helpful in realizing organizational goal or intention of the manager. Due to complexity in human actions, behavior control has always been the hot point in research of scholars home and abroad such as theories of motivation in early days and motivation theories which is rich in content. As the research paper of mathematical model of behavior control mechanism, this thesis has made summary and introduced math tools and modeling method that are commonly used in most behavior control models home and abroad at present and specified characters of these methods or applicable research scope. Based on this, the thesis has introduced payment and contract model, reputation model, measurement model of arousal effects as well as satisfaction evaluation model.
\end{abstract}

\section{Introduction}

Conducting quantitative analysis on behavior control through math model, on one hand, behavior control has been run through the accurate and objective thinking method of math so that recognition on management and human behaviors has no longer been ambiguous; on the other hand, various relations deduced from math model can date back to prerequisite and logical relation on each step, it is not difficult to find any negligence and leaks that may exist, avoid errors in control scheme and discuss optimization among measures. Therefore, in research of behavior control, many scholars have obtained many rigorous and systematic achievements in research through math model which guide practice.

\section{Composite pattern of incentive mechanism}

Different incentive combinations and different functions of incentive mechanism will have influences on arousal effects, therefore, some scholars put forward that driving source not only select inducements but consider incentive combination that maximizes arousal effects and method that incentive works, these two parts combine to achieve optimal arousal effects.

According to research of theory of the firm, there are three incentives in enterprises to employees: the first is the influence of enterprises on employees, that is, attractiveness of self-image and popularity of the company on employees; the second is the treatment that the company provides for the employees in economy(such as salary, bonus as well as subsidies), which is referred to as effect of economic regulation. The third is the treatment that the company provides for the employees in enjoying and using company powers, which is referred to as effect of power regulation. These three modes of regulation have different combinations, which could both function jointly and function in stages. These three regulation combinations are:

Incentive model 1: (S,Q,R), incentive model 2: $(\mathrm{S},(\mathrm{Q}, \mathrm{R})$ ) as well as incentive model 3 ( , $(\mathrm{R}, \mathrm{Q})$ ).

In which S represents attractiveness of company image to employees, that is influence of effect; Q represents effect of economic regulation; $\mathrm{R}$ represents effect of power incentive. Adopting systematic analysis approach, structure of synchronous system with incentive model 1 is as follows: 


\section{Satisfaction evaluation model}

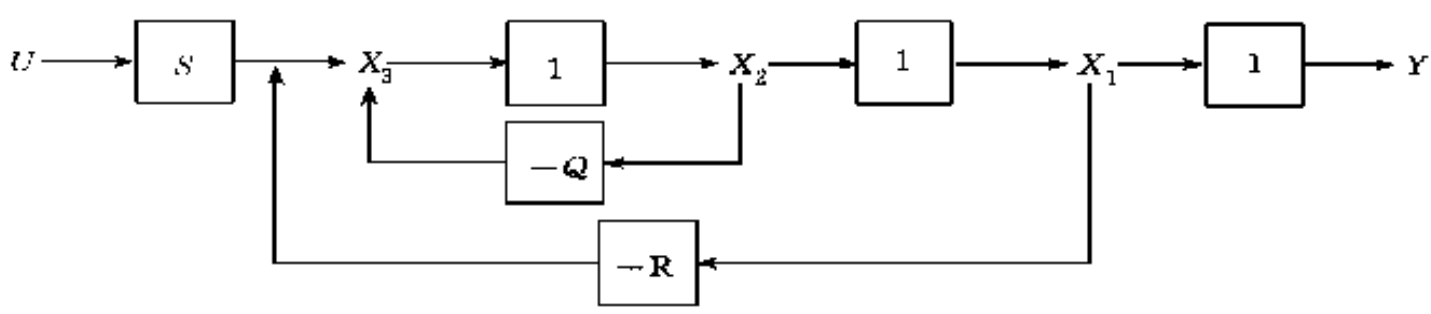

Fig. 1 synchronous system model with incentive model 1

In this Figure, U represents system input, which refers to number of employees that enters into the system and the company believes that it requires to provide incentives to leave them, $\mathrm{Y}$ represents system output, which refers to number of employees that finally leave the company due to all incentives do not work, $\mathrm{Xi}$ is the intermediate variable in system analysis. We could get function of incentive model 1 which could be shown in mathematical function according to transfer equation of dynamic system:

$\mathrm{F}=\frac{S}{1+Q+R}$

Expression of output function is $\mathrm{Y}_{1}=\frac{S}{1+Q+R} \cdot \mathrm{U}$

This is the final result produced by incentive combination mechanism above. Then look at the incentive model 2, that is, to implement economic incentive first to those who are failed in influence of company image, and then power incentive if failed, the power incentive measure can be only carried out on those employees who are failed in economic incentive. Here is the structure chart of incentive system:

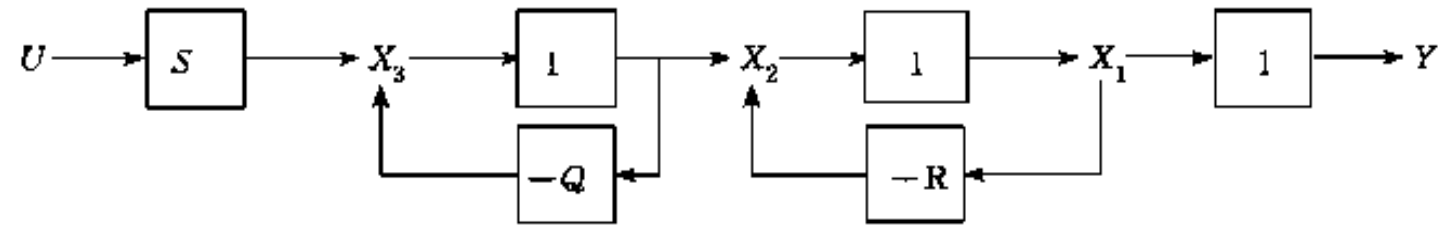

Fig. 2 system model of incentive model 2

Similarly, we could get the performance function of this system: $\mathrm{F}=\frac{S}{(1+Q)(1+R)}$

System output is: $\mathrm{Y}_{2}=\frac{S}{(1+Q)(1+R)} \cdot \mathrm{U}$

This is the final result produced by the second incentive combination mechanism.

In incentive model 3, to implement power incentive first to those who are failed in influence of company image, and then economic incentive if failed, here is the structure chart of incentive system as follows:

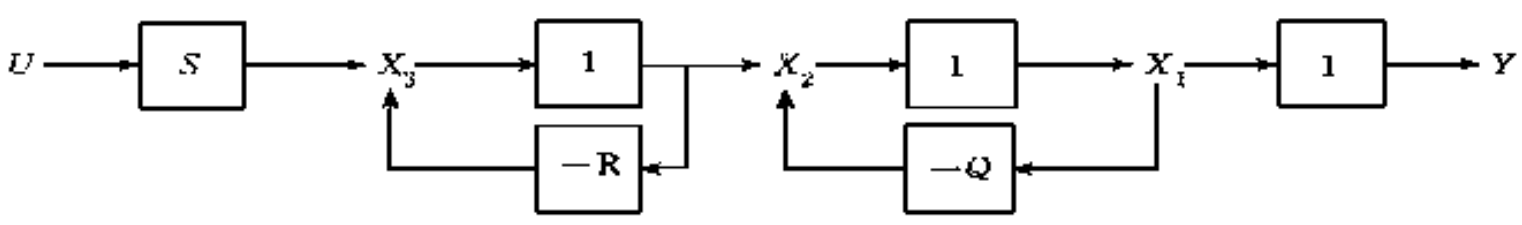

Fig. 3 system model of incentive model 3

Similarly, the performance function of system is $\mathrm{F}=\frac{S}{(1+R)(1+Q)}$

System output is $\mathrm{Y}_{3}=\frac{S}{(1+R)(1+Q)} \cdot \mathrm{U}$

Comparing (1),(2)as well as(3),due to: 


$$
\frac{S}{1+Q+R}>\frac{S}{(1+Q)(1+R)}, \frac{S}{(1+Q)(1+R)}=\frac{S}{(1+R)(1+Q)} \quad(0 \leq \mathrm{Q}, \mathrm{R}, \mathrm{S} \leq 1)
$$

Therefore, $\mathrm{Y}_{1}>\mathrm{Y}_{2}, \mathrm{Y}_{2}=\mathrm{Y}_{3}$.

Therefore, we could see from the result of systematic analysis of incentive mechanism theoretically that compared with using those two incentive measures simultaneously, applying economic incentive measure and power incentive measure distinguishingly can reduce proportion of loss of members in system more effectively; whether implementing economic incentive first or power incentive first, its arousal effects are the same. In actual business operation, the manager should implement economic incentive measure and power incentive measure respectively aiming at different people according to their personal capacities, working performance as well as personal development target, that is, only one incentive at present does not work and requires to carry out the next incentive measure, this is characterized by higher effectiveness and lower cost.

Satisfaction evaluation model. Incentive is the action adopted to stimulate others or oneself to accomplish an expected behavior process, it is based on meeting certain personal requirements and its result is to ask one individual to have satisfaction and sense of equity about behavior result. Satisfaction of people is based on utility acquired according to utility value theory, large utility value means high satisfaction. While judgment on size of utility is valuation of satisfaction on self-requirements based on certain reference point. Base on this, Yang Nai Ding (2000) has put forward satisfaction evaluation model.

Suppose that $\mathrm{X}_{\mathrm{ij} 1}, \mathrm{X}_{\mathrm{ij} 2}, \ldots \mathrm{X}_{\mathrm{ijn}}$ is the satisfaction of requirement status of employee $\mathrm{i}$ obtained from $n$ in enterprise $j$, then the satisfaction $S_{i p r}$ of employee $i$ obtained from enterprise $p$ relative to enterprise $r$ is:

$\mathrm{S}_{\mathrm{ipr}}=\sum_{k=1}^{n} a_{i k} \cdot u_{i}\left(x_{i p k}-x_{i r k}\right)$

In which $u_{i}(x)$ represents utility function of employee. If $x \geq 0$, then $u_{i}(x) \geq 0$; if $x<0$, then $u_{i}(x)<0$. $\mathrm{A}_{\mathrm{ik}}$ represents satisfaction coefficient, $0 \leq \mathrm{a}_{\mathrm{ik}} \leq 1$ and $\sum_{k=1}^{n} a_{i k}=1$.

We could see from the above model that employees satisfaction depends on relative level of meeting requirements, size of employees satisfaction is influenced by selection of reference point while selection of reference point is a selection process involved in subjectivity and objectivity, which is influenced by various psychological preferences. For instance, some people may choose enterprise in good treatment as the reference for salary increase while some people may take those who are inferior to them as the reference for psychological satisfaction. Therefore, as the enterprise, it should set and lead employees to select reasonable reference point according to principal of enterprise target and lead determination of demand index coefficient $a_{\text {ik }}$ of employees to make demands of employees consistent with realization of enterprise target as much as possible.

$\left|u\left(x_{i p k}-x_{i r k}\right) \neq\right| u\left(x_{i r k}-x_{i p k}\right)$, that is, when people lose certain fortune, their utility evaluation on this fortune is larger than that of equivalent fortune, that is, if $x_{i p k}-x_{i r k}>0$, then $\left|u\left(x_{i p k}-x_{i r k}\right)\right|<\left|u\left(x_{i r k}-x_{i p k}\right)\right|$. Therefore, if this enterprise is not as good as the reference, then it must compensate inefficiency in previous index with more amount of meeting demands on another index.

\section{Summary}

One important field in research of behavior control--payment, personal behavior, relative scarcity of factors, human demands preferences as well as various forces outside the market including nature, society as well as politics function all together on design of payment and achieve instantaneous balance. This balance is the result of various forces at the same time influences on subsequent distribution of income. Process of payment design is a successive balance. Furthermore, payment belongs to a kind of causality in circular chain. It is always difficult in choosing one or more forces 
and putting forward hypothesis based on this and deducing the distribution relations as a whole unidirectionally. It should be based on successive balance of causality chain to describe distribution of income rationally.

\section{References}

[1] Holmstorm B. Moral hazard in teams. The bell Journal of Economics, 1982,13(2): 324-340

[2] Aggarwal A, G. Mandelker. Managerial incentives and corporate investment and financing decisions. Journal of Finance, 1987,42(4): 823-837.

[3] Berle A, G.C. Means. The Modern Corporation and private property. New York, 1932.

[4] Boyer, M., and J.J.Laffont. Competition and the Reform of Incentives in the Public Sector. Journal of Public Economics, 2000.

[5] Fama E. Agency problem and the theory of the firm. Journal of Political Economy, 1980,88(2): 288-307.

[6] Grossman S, Hart.An analysis of the principal-agent problem. Econometrica, 1983, 5: 7-45.

[7] Holmstrom B.Moral hazard and observability. The Bell Journal of Economics, 1979,10:74-91. 